\title{
THE EFFECT OF FAT RICH DIET AND ALCOHOL ON ION CONCENTRATION IN BILE FLUID IN RATS
}

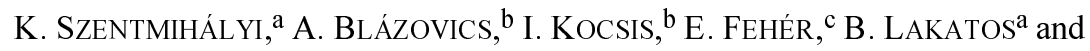 \\ P. VINKLER ${ }^{\mathrm{a}}$ \\ ${ }^{a}$ Chemical Institute, Chemical Research Center, Hungarian Academy of Sciences, \\ H-1025 Budapest, Pusztaszeri út 59-67. Hungary \\ ${ }^{b}$ 2nd Department of Medicine, Semmelweis University, H-1085 Budapest, Üllöi út 26. Hungary \\ ${ }^{c}$ 2nd Department of Anatomy, Semmelweis University, H-1085 Budapest, Üllői út 26. Hungary
}

(Received: 12 April 2000; accepted: 23 June 2000)

The metabolic alteration of fatty liver causes significant changes in the composition of bile fluid secreted by epithelial liver cells. These processes include both organic molecular and inorganic ion content changes in bile juice as well. In this work ion concentration differences of bile fluid in experimental hyperlipidemic rats compared to normal ones were monitored. Fatty liver in young male Wistar albino rats was induced by $2 \%$ cholesterol, $20 \%$ sunflower oil and $0.5 \%$ cholic acid added to the normal food and $3 \%$ alcoholic water was administered to rats for 9 days. The development of hyperlipidemy was detected by measuring serum parameters and fatty liver was proved by morphological investigations. The ion concentrations of bile fluid samples were determined by ICP-OES (inductively coupled plasma optical emission spectrometry). The bile fluid samples were digested with a mixture of $\mathrm{HNO}_{3}$ and $\mathrm{H}_{2} \mathrm{O}_{2}$. The results show that the concentration of calcium and phosphorus in bile juice increased significantly in hyperlipidemic rats compared to the control. Significant concentration changes have also been detected for chromium and manganese. The changes in metal ion metabolism also point to the damage of liver cells owing to metal complex evacuation.

Keywords: fatty liver, metal-, phosphorus- and sulfur concentration

Similarly to the development of alcoholic fatty liver, the fat rich diet may also cause changes in the lipid metabolism and lead to fatty liver (YAGASAKI, 1998). In the case of liver damage significant changes occur in the metabolism of macro-, meso- and micro elements, amino acid, proteins/enzymes and fatty acids, vitamin supplementation and in the oxidation state of cells (FREEMAN \& CRAPO, 1982; BENDICH, 1990; LIEBER, 1991; 1997; BLÁZOVICS et al., 1992; 1997).

Hypomagnesemia, hypokalemia, hypoparathyreodism and hypophosphatemia are common features of alcoholic fatty liver, alcoholic and other cirrhosis (BoGIN et al., 1986; GLEESON et al., 1994). Decrease of the magnesium level in serum, erythrocyte, 
lymphocyte, liver tissue, heart muscle, skeleton muscle and bone is well known (FLINK et al, 1979; COHEN, 1990). Magnesium depletion from the heart muscle and liver tissues is the fastest process. Another well known symptom, zinc deficiency in liver tissues in the case of fatty liver is due to decreased zinc absorption and elevated depletion of zinc by zinc-amino acid in urine (ORLANDO et al., 1987). Contrary to this, in alcoholic liver damage zinc enzymes with adequate activity are required for the elimination of alcohol. The liver tissues may be damaged not only by metabolized alcohol and acetaldehyde but also by the electrolyte concentration changed in bile fluid. The bile salts injure the liver membranes and the effects are linear to the concentration and hydrophobicity of salts of bile acids (STRANGE, 1984, LIEBER, 1997).

Various functions of liver, e.g. the excretion of bile fluid and the storage of minerals and one of its most important functions, detoxification, may also be impaired.

The aim of this work was to study how ion concentration changes in bile fluid in alimentary induced hyperlipidemy in rats compared to normal rats.

\section{Materials and methods}

\subsection{Animal experiments}

Young male Wistar albino rats (150-200 g wt.) were used in this "short term" experiment. The animals were divided into two groups, each consisting of 10 animals. The animals in group I were fed with normal food (BIOFARM PROMT, BFP Kft, Hungary). The animals in group II were fed with fat rich diet containing $2.0 \%$ cholesterol, $20 \%$ sunflower oil and $0.5 \%$ cholic acid added to the normal food (BIOFARM PROMT), and 3\% alcoholic water was administered to the rats. The animals were kept on the diets for 9 days.

The rats were anaesthetized with urethane $\left(1 \mathrm{~g} \mathrm{~kg}^{-1}\right)$ for deep narcosis $\left(1.2 \mathrm{~g} \mathrm{~kg}^{-1}\right)$. The livers of the two groups were subjected to morphological investigations. After laparotomy the biliary duct was cannulated with a plastic cannula. The bile was collected in a plastic tube for $2 \mathrm{~h}$. After operation the animals were killed by decapitation in general anesthesia.

\subsection{Histological method}

Specimens of the liver were prepared for electron microscopy. Small pieces of the organ were fixed in $4 \%$ paraformaldehyde and a $1 \%$ glutaraldehyde-containing fixative solution, postfixed in $1 \% \mathrm{OsO}_{4}$ and embedded in Durcupan. Ultrathin sections were stained with uranyl acetate and lead citrate and examined with a Tesla BS 500 electronmicroscope. 


\subsection{Biochemical investigations}

Standard spectroscopic methods of DIAGNOSTICUM were used to determine the serum parameters: alkaline phosphatase (ALP), aspartate-transaminase (AST), alanine-transaminase (ALT), gamma-glutamyl-transpeptidase $(\gamma$-GT), cholesterol (CHOL), triglycerides (TG).

\subsection{Determination of element content}

Element concentrations in the bile fluid were determined by ICP-OES (inductively coupled plasma optical emission spectrometer). Type of instrument: Atom Scan 25 (Thermo Jarrell Ash), a sequential plasma emission spectrometer.

The following 23 elements were determined in three parallel measurements: $\mathrm{Al}$, As, Ba, Ca, Cd, Co, Cr, Cu, Fe, Hg, K, Li, Mg, Mn, Mo, Na, Ni, P, Pb, S, Ti, V, Zn. Three times three sec. integration time, blank subtraction and background correction were applied during the measurements. Standard solutions were made from Merck ICP standards. Standard solutions in different concentrations $\left(0,1,5,10,20,50 \mu \mathrm{g} \mathrm{ml}^{-1}\right)$ were measured for calibration curves. Since ICP measurements have matrix effect, the standards were prepared in the same matrix (in $5 \% \mathrm{HNO}_{3}$ solutions) as the samples.

For measurements, the bile fluid samples $(2.0 \mathrm{~g})$ were digested with a mixture of $\mathrm{HNO}_{3}(5 \mathrm{ml})$ and $\mathrm{H}_{2} \mathrm{O}_{2}(3 \mathrm{ml})$ in teflon vessels. After digestion the samples were diluted to $25 \mathrm{ml}$ with deionised water.

\subsection{Statistical analysis}

Means and standard deviations (SD) were calculated from the results. For comparison of the means one way analysis of variance (ANOVA) was used by GraphPAD software version 1.14 (1990).

\section{Results}

The changes in the serum parameters of rats due to fat rich diet indicate liver damage. Significant elevations in alkaline phosphatase, aspartate-transaminase, alaninetransaminase, gamma-glutamyl-transpeptidase and cholesterol were observed $(\mathrm{P}<0.05)$, while the changes in triglycerides were not significant (Table 1).

Morphological investigations also point to fatty degeneration, balloon cell degeneration, centrilobular fatty degeneration, necrosis and vacuolization. Electron microscopic pictures of liver cells of animals fed with fat rich diet had extremely variable appearance, which reflects to some extent the functional state of the cell. 


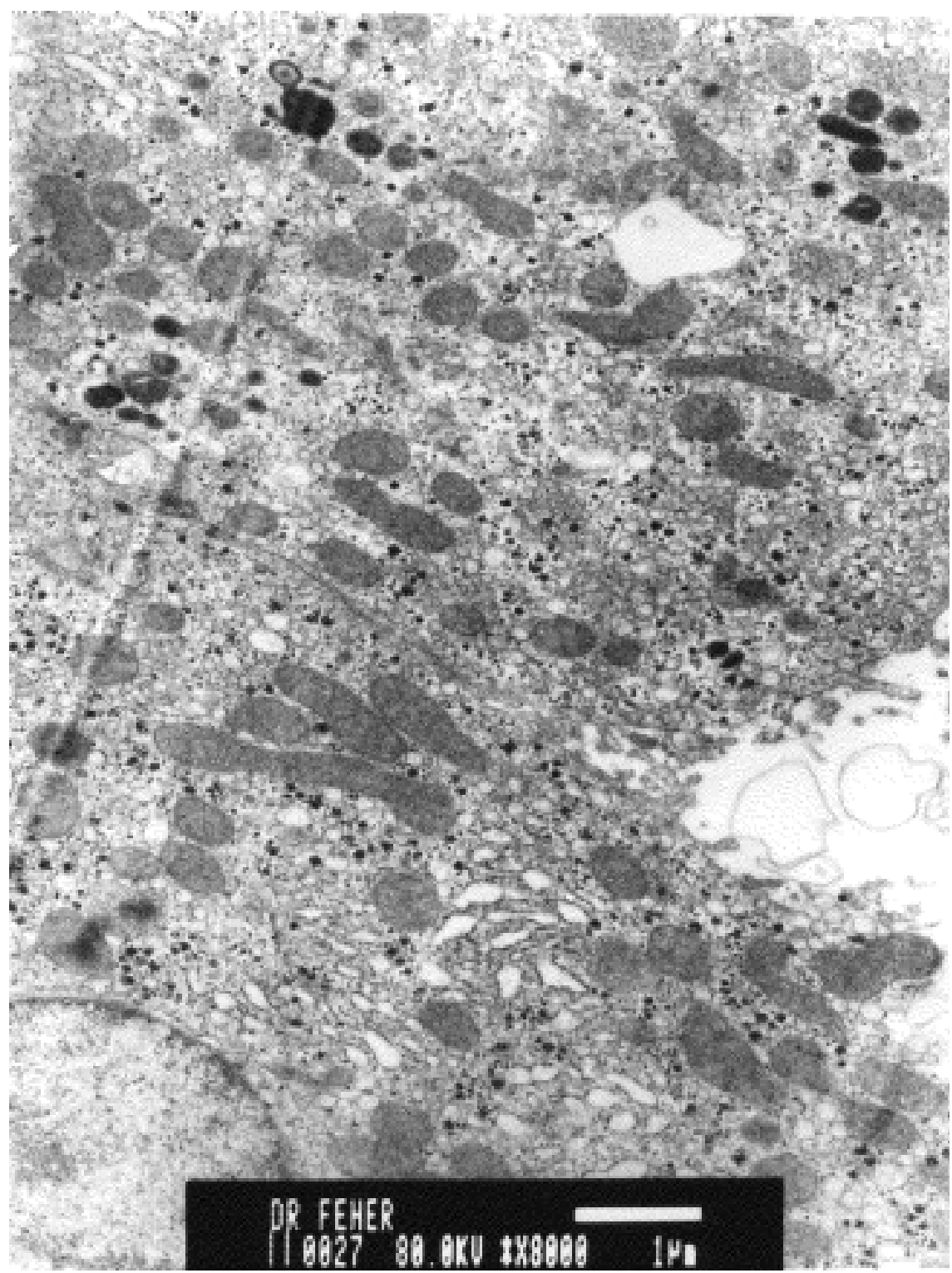

Fig. 1a. Electron microscopic picture of rat normal hepatocyte (Bar scale $1 \mu \mathrm{m})$ 


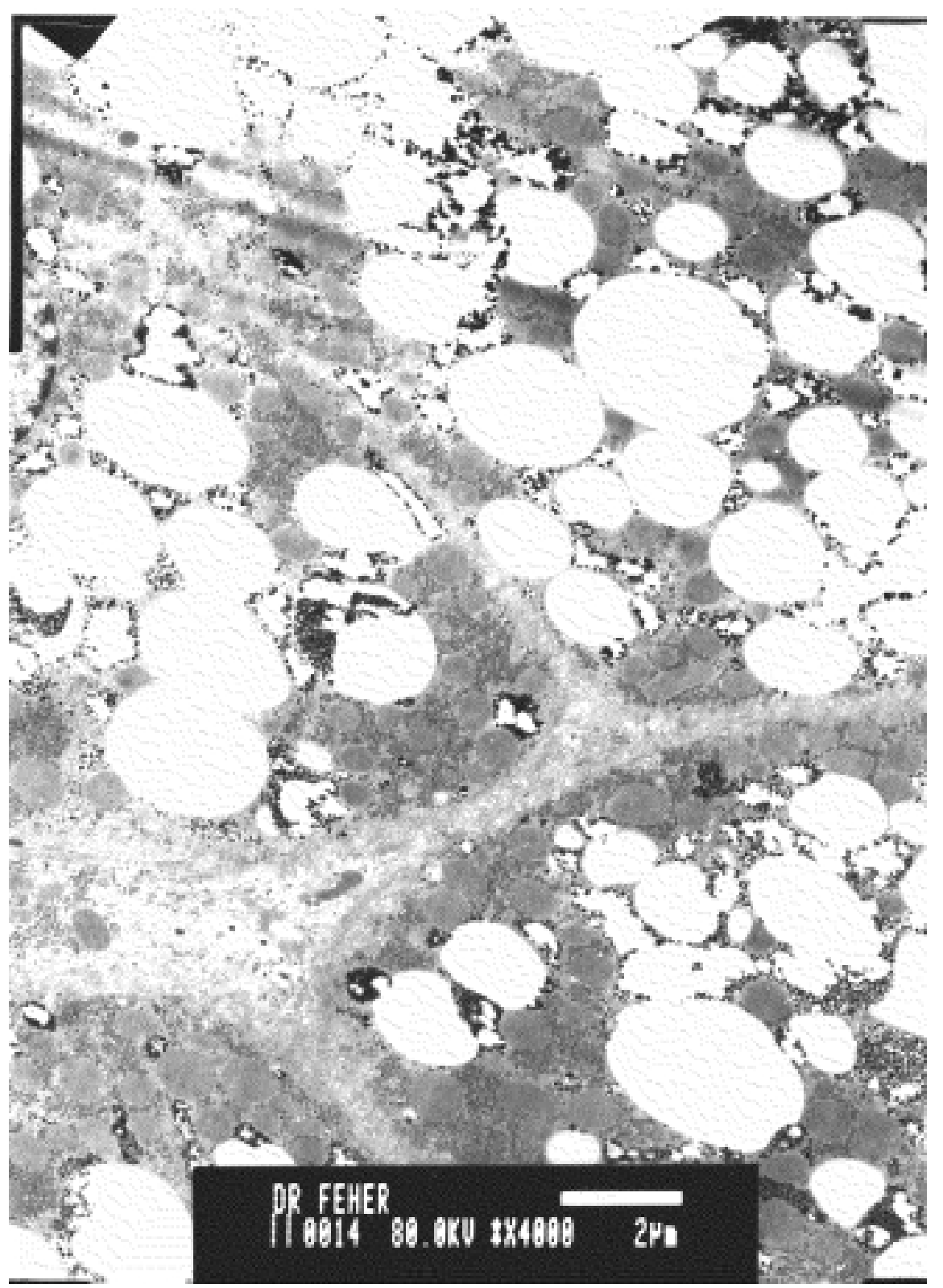

Fig. 1b. Electron microscopic picture of rat hepatocyte containing a large number of lipid dropplets after fat rich diet (Bar scale $2 \mu \mathrm{m}$ ) 
The decrease in the glycogen content of hepatic cells points to liver injury. Glycogen is replaced by lipids in proportion to the decrease in quantity. In the cytoplasm large vacuoles can be seen. An accumulation of various sized lipid droplets up to $5 \mu \mathrm{m}$ in diameter was observed in the cytoplasm of hepatocytes in the fatty liver (Fig. 1b). Normal hepatocyte is shown for comparison (Fig. 1a).

Table 1

Serum parameters and \pm standard deviations in control and hyperlipidemic rats

\begin{tabular}{lccc}
\hline Parameters & $\begin{array}{c}\text { Control rats } \\
\mathrm{n}=10\end{array}$ & $\begin{array}{c}\text { Hyperlipidemic rats } \\
\mathrm{n}=10\end{array}$ & $\begin{array}{c}\text { Significance } \\
\end{array}$ \\
\hline ALP $\left(\mathrm{U} \mathrm{l}^{-1}\right)$ & $580 \pm 169$ & $1941 \pm 28$ & $\mathrm{~s}$ \\
AST $\left(\mathrm{U} \mathrm{l}^{-1}\right)$ & $309 \pm 74$ & $199 \pm 46$ & $\mathrm{~s}$ \\
ALT $\left(\mathrm{U} \mathrm{l}^{-1}\right)$ & $74.4 \pm 7.8$ & $102.4 \pm 11.7$ & $\mathrm{~s}$ \\
$\gamma$-GT $\left(\mathrm{U} \mathrm{l}^{-1}\right)$ & $0.80 \pm 0.44$ & $1.60 \pm 0.54$ & $\mathrm{~s}$ \\
CHOL $\left(\mathrm{mmol} \mathrm{l}^{-1}\right)$ & $1.92 \pm 0.57$ & $11.14 \pm 0.63$ & $\mathrm{~s}$ \\
TG $\left(\mathrm{mmol} \mathrm{l}^{-1}\right)$ & $1.24 \pm 0.58$ & $1.01 \pm 0.32$ & $\mathrm{~ns}$ \\
\hline
\end{tabular}

s: significant, $\mathrm{P}<0.05$

ns: not significant, $\mathrm{P}>0.05$

Measurements of the elements were carried out according to the linear calibration curves. The concentration of $\mathrm{Al}, \mathrm{Co}, \mathrm{Li}, \mathrm{Ti}$ and $\mathrm{V}$ is below detection limit in both sample groups. The results show that the concentration of calcium and phosphorus in bile juice increases significantly in hyperlipidemic rats compared to the control (Table 2). The changes in metal ion metabolism also point to the damage of liver cells owing to the evacuation of metal complexes. The elevated potassium depletion is not significant although this suggests the damage of liver cell membranes. Interestingly, the concentration of magnesium, iron and zinc in the bile fluid of rats has not changed significantly.

Other significant concentration changes have been observed for chromium and manganese. The quantity of these elements was found to be lower in the bile fluid of rats with hyperlipidemic liver compared to normal rats.

\section{Conclusions}

The concentration of some elements $(\mathrm{Al}, \mathrm{Co}, \mathrm{Li}, \mathrm{Ti}$ and $\mathrm{V})$ in bile fluid is very low. Significant concentration changes were observed for calcium, chromium, manganese and phosphorus. These concentration changes of elements show liver damage caused by elevated alimentary fat. The results obtained from the measurements 
of element concentration in bile fluid confirm the data obtained from serum parameter and microscopic investigations.

The elevated element content of bile juice in hyperlipidemic rats shows essential metal ion evacuation from liver. The evacuation of phosphorus is particularly dangerous, since this element is essential in energy transfer. Eleveted phosphorus evacuation in bile may be an explanation for hypophosphatemia in fatty liver. Elevated potassium depletion is not significant although this indicates the damage of liver cell membranes.

Table 2

Element concentration $\left(\mu \mathrm{g} \mathrm{g}^{-1}\right)$ in bile fluid for control and hyperlipidemic rats

\begin{tabular}{|c|c|c|c|}
\hline Parameters & $\begin{array}{l}\text { Control rats } \\
\qquad n=10\end{array}$ & $\begin{array}{l}\text { Hyperlipidemic rats } \\
\qquad \mathrm{n}=10\end{array}$ & Significance \\
\hline As & $0.490 \pm 0.132$ & $<0.5$ & ns \\
\hline $\mathrm{Al}$ & $<0.5$ & $<0.5$ & ns \\
\hline $\mathrm{Ba}$ & $0.484 \pm 0.808$ & $0.155 \pm 0.149$ & ns \\
\hline $\mathrm{Ca}$ & $41.14 \pm 30.89$ & $83.16 \pm 7.67$ & s \\
\hline $\mathrm{Cd}$ & $0.131 \pm 0.116$ & $0.088 \pm 0.033$ & ns \\
\hline $\mathrm{Co}$ & $<0.05$ & $<0.05$ & ns \\
\hline $\mathrm{Cr}$ & $0.177 \pm 0.0034$ & $<0.05$ & s \\
\hline $\mathrm{Cu}$ & $0.794 \pm 0.434$ & $0.430 \pm 0.246$ & ns \\
\hline $\mathrm{Fe}$ & $2.55 \pm 0.75$ & $1.48 \pm 0.81$ & ns \\
\hline $\mathrm{Hg}$ & $0.352 \pm 0.112$ & $0.246 \pm 0.138$ & ns \\
\hline $\mathrm{K}$ & $181.4 \pm 15.6$ & $201.2 \pm 13.3$ & ns \\
\hline $\mathrm{Li}$ & $<0.05$ & $<0.05$ & ns \\
\hline $\mathrm{Mg}$ & $26.93 \pm 5.91$ & $20.83 \pm 2.49$ & ns \\
\hline $\mathrm{Mn}$ & $0.200 \pm 0.095$ & $0.073 \pm 0.037$ & s \\
\hline Mo & $0.294 \pm 0.050$ & $0.259 \pm 0.216$ & ns \\
\hline $\mathrm{Na}$ & $3997 \pm 550$ & $3718 \pm 175$ & ns \\
\hline $\mathrm{Ni}$ & $<0.1$ & $0.339 \pm 0.335$ & ns \\
\hline $\mathrm{P}$ & $148.2 \pm 22.2$ & $263.6 \pm 19.0$ & s \\
\hline $\mathrm{Pb}$ & $2.26 \pm 0.84$ & $1.88 \pm 0.46$ & ns \\
\hline $\mathrm{S}$ & $759.3 \pm 351.6$ & $532.4 \pm 52.5$ & ns \\
\hline $\mathrm{Ti}$ & $<0.05$ & $<0.05$ & ns \\
\hline $\mathrm{V}$ & $<0.05$ & $<0.05$ & ns \\
\hline $\mathrm{Zn}$ & $0.0876 \pm 0.0735$ & $0.263 \pm 0.077$ & ns \\
\hline
\end{tabular}

S: significant, $\mathrm{P}<0.05$

ns: not significant, $\mathrm{P}>0.05$ 
The decrease of chromium- and manganese concentration in the bile fluid of rats with hyperlipidemic liver compared to normal rats suggests that the liver is not able to carry out its function of detoxification. The liver probably accumulates these elements, thus the concentration of these elements is lower in bile fluid in hyperlipidemic rats. Although iron concentration change in bile is not significant, nevertheless, the decrease of it in bile with fatty liver may indicate the accumulation of this element in liver as described by CHETTY and co-workers (1999).

Magnesium depletion from liver tissues is one of the fastest processes. Interestingly, the concentration of magnesium in the bile fluid of rats has not increased. Presumably, in hyperlipidemy the magnesium concentration in liver cells is so low that the amount of magnesium in bile fluid cannot surpass the normal value. Magnesium depletion is an extremely fast process, presumably occurring before liver injury can be observed, therefore, it could not be monitored in our experiments.

It may be concluded that liver damage may also be caused by fat rich diet and monitored by the ion concentration in bile fluid.

\section{References}

BENDICH A. (1990): Antioxidant micronutrients and immune responses. Ann. N. Y. Acad. Sci., 587, 169-180. BLÁZOVICS, A., FEHÉR, E. \& FEHÉR, J. (1992): Free radical reactions in experimental hyperlipidemia in pathomechanism of fatty liver. -in: CSOMÓS, G.\& FEHÉR, J. (Eds). Free radical and liver. SpingerVerlag, Berlin, pp. 96-126.

BlÁzovics, A., ÖRSI, F., KEMÉNY, T., FEHÉR, E., BARTA, I. \& FEHÉR, J. (1997): Lipids and lipid peroxidation in liver, bile and gallbladder. Progress in Hepato Pharmacology, 2, 103-116.

BOGIN, E., AVIDAR, Y. \& MEROM, M. (1986): Biochemical changes in liver and blood during liver attering in rats. J. clin. Chem. clin. Biochem., 24, 621-626.

ChETTy, K. N., CONWAy, R., HARRIS, K. C., DORSEy, W. C., Hill, D., ChETTy, S., YerRAPRAGADA, R. \& JAIN, S. (1999): Dietary supplementation with oil influences iron concentrations in rats. Nutr. Res., 19, 1665-1670.

COHEN, I. (1990): Magnesium and liver cirrhosis. Metal Ions Biol., 26, 271-284.

Flink E. B., SHANE, S. R., SCOBBO, R. R., BleHSCHMIDT, N. G. \& MCDOWELl, P. (1979): Relationship of free fatty acids and magnesium in ethanol with drawal in dogs. Metabol., 28, 858-864.

FREEMAN, B. \& CRAPO J. D. (1982): Biology of disease, free radicals and tissue injury. Lab. Invest., 47, $412-426$.

GLEESON, D., MuRPHY, G. M. \& DOWLinG, R. H. (1994): Changes in serum calcium levels influence biliary calcium levels in humans. Gastroenterology, 107, 1812-1818.

LIEBER, C. S. (1991): Hepatic, metabolic and toxic effects of ethanol: Update alcoholism. Clin. Exp. Res., 15, 573-592.

LIEBER, C. S. (1997): Ethanol metabolism, cirrhosis and alcoholism. Clin. Chem. Acta, 257, 59-84.

ORLANDO, R., TONOSE, G., DE FINO, M. \& CANGIANO, F. (1987): Changes in serum zinc levels during cronic liver disease. Minerva Med., 78, 1759-1763.

STRANGE, R. C. (1984): Hepatic bile flow. Physiol. Rev., 64, 1055-1102.

YAGASAKI, K. (1998): Dietary control of abnormal lipid metabolism secondary to hypothyroidism, cancer and inflammatory disease. Recent Res. Dev. Lipids Res., 2, 21-28. 